\title{
DESEMPENHO DE CONCRETOS DE ESCÓRIA DE ACIARIA FRENTE A ATAQUE DE CLORETOS
}

\author{
FERRREIRA, LARISSA \\ Graduanda em Engenharia Civil \\ Universidade Federal de Ouro Preto \\ Minas Gerais; Brasil \\ larissa.caroline@aluno.ufop.edu.br
}

\section{COSTA, LAÍS}

Doutoranda em Engenharia Civil

Universidade Federal de Ouro Preto

Minas Gerais; Brasil

lais.cristina.costa@gmail.com

\section{PEIXOTO, RICARDO}

Engenheiro Civil, D.Sc

Universidade Federal de Ouro Preto

Minas Gerais; Brasil

fiorotti.ricardo@gmail.com
NOGUEIRA, MARCELA

Mestranda em Engenharia Civil

Universidade Federal de Ouro Preto

Minas Gerais; Brasil

marcelaanogueira@outlook.com

MOURA, SANDRA

Médica Veterinária, D.Sc

Universidade Federal de Ouro Preto

Minas Gerais; Brasil

sandramoura@gmail.com

\section{RESUMO}

É crescente o emprego de resíduos para fabricação de matrizes cimentícias de alto desempenho, nesse sentido é fundamental a avaliação da sua durabilidade. O Brasil possui grande extensão litorânea estando as estruturas de concreto armado sujeitas a penetração de cloreto. Nesse sentido, destaca-se a escória de aciaria, resíduo que vem sendo incorporada em concretos. Assim, o presente estudo avaliou a durabilidade de concretos produzidos com escória de aciaria frente a ataque de cloretos. A escória de aciaria foi utilizada como agregado (miúdo e graúdo) e adição mineral. Para comparação, produziu-se concretos sem adição e com agregados de referência. As matrizes foram caracterizadas física e mecanicamente. A resistência ao ataque de cloretos foi analisada, expondo os corpos de prova em solução de $\mathrm{NaCl}$ em períodos de 35 e 55 dias para avaliar a profundidade de penetração desses cloretos. Verificou-se, que os concretos com agregados de escória de aciaria apresentaram maiores resistências à compressão quando comparado aos convencionais. Em relação a durabilidade, a adição mineral de escória de aciaria reduziu a profundidade de penetração de Cl. Assim, os resultados indicam viabilidade técnica da utilização da escória de aciaria como agregado e adição mineral.

Palavras-chave: Escória de aciaria, Concreto, Sustentabilidade, Durabilidade, Ataque de cloretos.

\section{ABSTRACT}

The use of residues to produce high performance cementitious matrices is increasing, then the evaluation of its durability is essential. Brazil has great coastal extension and the reinforced concrete structures are subject to chloride penetration. In this sense, the steel slag stands out, a residue that has been incorporated into concrete. The present study evaluated the durability of concrete produced with steel slag against chloride attack. Steel slag was used as aggregate (fine and coarse) and mineral addition. For comparison, concretes without addition and with reference aggregates were produced. The matrices were physically and mechanically characterized. Chloride attack resistance was analyzed by exposing the specimens in $\mathrm{NaCl}$ solution at 35 and 55 days to evaluate the penetration depth of these chlorides. It was found that concretes with steel slag aggregates showed higher compressive strengths when compared to conventional ones. Regarding durability, the addition of steelmaking slag reduced the $\mathrm{Cl}$ penetration depth. Thus, the results indicate the technical feasibility of using the melt slag as aggregate and mineral addition.

Keywords: Steel slag, Concrete, Sustainability, Durability, Chloride attack. 


\section{INTRODUÇÃO}

A construção civil possui uma alta demanda por agregados inertes e a sua produção é uma atividade extrativa com significativo consumo de recursos. Em 2015, a indústria da construção brasileira consumiu mais de 741 milhões de toneladas de agregados (ANEPAC, 2015). Enquanto, a indústria siderúrgica brasileira gerou no ano de 2017, 20,9 milhões de toneladas de resíduos e coprodutos, sendo $27 \%$ escória de aciaria (IABR, 2018). Conciliar, a geração de resíduos siderúrgicos com as demandas da construção civil principalmente através da implementação em matrizes cimentícias. Assim, pretende-se auxiliar na diminuição o consumo de recursos naturais, reintroduzindo esses resíduos na cadeia produtiva, além de reduzir as áreas para sua deposição.

Paralelo a isso, sabe-se que o Brasil possui uma das vinte maiores costas marítimas do mundo, com $7.491 \mathrm{~km}$. Um dos grandes problemas relacionados a essa extensão litorânea são os reparos em estruturas de concreto que sofrem com a corrosão das armaduras causada pela penetração de cloretos. Os íons cloretos penetram no concreto, principalmente por difusão, ocasionando diminuição da seção de aço e fissuração do concreto (YOUNG, FRANCIS e MINDESS, 1998; GENG, XU, et al., 2010). Segundo, a normalização brasileira para projetos em concreto armado, NBR 6118 (ABNT, 2013), a maior classe de agressividade é para estruturas que estão diretamente em contato com respingos do mar. Portanto, em ambientes agressivos, como as regiões marítimas, é fundamental a utilização de concretos que tenham alto desempenho e durabilidade.

A deterioração de estruturas produzem gastos significativos, assim aumentar a vida útil dessas edificações se torna uma boa solução, principalmente a longo prazo. Permitindo reduzir os impactos e gerar economia de recursos e energia. Além disso, durabilidade está intimamente relacionada com sustentabilidade, não só pelo fato de reduzir reparos, mas, porque em busca da durabilidade maior podem ser adotadas algumas estratégias, como a reciclagem de resíduos produzidos em outros setores, como é o caso do uso da escória de aciaria. Desse modo, as adições minerais ao cimento Portland, como as escórias e pozolanas, são soluções adequadas para se obter concretos de qualidade técnica e econômica (MEDEIROS, M. H. F., ET AL., 2011; BERTOLINI, L. ET AL., 2016).

Com essa motivação, estudos com a utilização da escória de aciaria como agregado e adição mineral para concreto já vêm sendo realizados e apresentam-se como uma solução com possível viabilidade econômica, técnica e ambiental. Monosi et al (2016), San José et al (2014), Biskri et al (2017) e Souza (2016) avaliaram avaliaram a escória de aciaria como substituição parcial ao agregado ressaltando suas propriedades mecânicas e físicas superiores e/ou equivalentes aos convencionais. Quanto a durabilidade, não há um consenso dessa informação, pois Santamaria et al (2018) comprovou que concretos produzidos com agregados de escória de aciaria expostos a ambientes marítimos tem desempenho superior ao convencional, com menor penetração de íons cloreto. Enquanto que, Biskri et al (2017) e Arribas et al (2014), observaram que esses concretos apresentaram maior permeabilidade a esses íons cloreto e expansibilidade quanto as matrizes convencionais avaliadas.

Assim, o objetivo desse estudo é avaliar o desempenho de concretos expostos a ataque de cloreto produzidos totalmente com agregados e adição mineral de escória, buscando compreender e avaliar a influência desses materiais na durabilidade do concreto.

\section{METODOLOGIA}

\subsection{Materiais}

O cimento escolhido para fabricação dos concretos foi o CP IV RS 32, cimento pozolânico, cuja massa unitária é de 0,94 $\mathrm{g} / \mathrm{cm}^{3}$. A escolha desse cimento é para garantir estruturas duráveis a ataques de cloretos, sulfatos e reação álcali-agregado. Com relação aos agregados utilizados para os traços de referência foram a areia de rio, proveniente de Ponte Nova, e brita de gnaisse. Já para os concretos produzidos com escória de aciaria, foi utilizado a escória de aciaria do processo tipo LinzDonawitz (LD), descendente de uma siderúrgica em João Monlevade. Essa escória foi recebida com diâmetro máximo característico de 12,5 mm e intemperizada através de ciclos de molhagem e secagem por quatro anos em pilhas. Esse resíduo foi posteriormente processado a fim de produzir o agregado (graúdo e miúdo) e adição mineral de escória de aciaria.

O aditivo utilizado foi o superplastificante (eterpolicarboxilico, MC Bauchemie Powerflow 1180) para permitir uma redução do fator água/cimento sem perda de trabalhabilidade dos concretos. Para os concretos de aciaria é importante essa busca, já que as escórias apresentam maior massa específica, principalmente, devido à sua composição química e a 
presença de óxidos metálicos, $\mathrm{Fe}_{2} \mathrm{O}_{3}$ (SILVA, SOUZA, et al., 2016). Além disso, foi utilizado água potável proveniente do sistema público de abastecimento de Ouro Preto.

\subsection{Métodos}

\subsubsection{Preparação dos Materiais}

O agregado miúdo de escória de aciaria foi obtido, através da fragmentação do material coletado no depósito de armazenamento pelo triturador de mandíbulas (Retsch BB 200) e submetido a separação da fração magnética por via seca em rolo magnético (Inbras CC $\varnothing 12$ x 12, intensidade 5000 Gauss), cujo realizou-se três repetições, obtendo, assim, uma fração não-magnética e outra magnética que era ao final descartada. A fração magnética correspondeu cerca de $30 \%$ da amostra. Essa escória processada foi separada gravimetricamente para se obter uma curva granulométrica que fosse compatível com NBR 7211 (2009), de acordo com a zona ótima.

Os agregados graúdos de escória de aciaria não precisaram ser fragmentados, mas foram submetidos a separação da fração magnética (igual ao do agregado miúdo de escória de aciaria) e gravimétrica por peneiramento, para que sua curva granulométrica fosse compatível com as exigências da norma NBR 7211 (2009). Quanto, os agregados convencionais (graúdo e miúdo) foram separados por peneiramento para obter uma curva granulométrica idêntica ao dos agregados de escória de aciaria (miúdo e graúdo), segundo a zona ótima da NBR 7211 (2009). Sendo possível, produzir concretos fisicamente semelhantes e entender a influência da composição do material nas suas propriedades.

Para refinar os poros, contribuindo positivamente na durabilidade do concreto, foi produzida uma adição mineral com escória de aciaria, denominada powder LD. Esse powder foi produzido a partir da cominuição da escória de aciaria. Inicialmente, a escória de aciaria foi submetida ao mesmo processamento da produção do agregado miúdo. Após isso, o material não-magnético passante na peneira de $4,75 \mathrm{~mm}$ foi fragmentada no moinho de bolas (Marconi MA500) por 3 horas a 200 RPM, utilizando esferas de aço inox. Ao final do processo, esse material foi refinado em um moinho planetário (Retsch PM100), com jarro e esferas de zircônio por 15 minutos a 400 RPM para, assim, obter a adição mineral, powder LD.

\subsubsection{Caracterização dos Materiais}

A escória de aciaria LD foi caracterizada através da sua composição química, cujo uma amostra foi fragmentada por 180 minutos no moinho de bolas a 200 RPM e 15 minutos no moinho planetário a 400 RPM, que fez com que fosse gerado um material passante na peneira de $0,045 \mathrm{~mm}$ e, assim, obtido a composição químicas destas pela fluorescência de raio-X (PANalytical Epsilon3x).

Os agregados foram caracterizados de acordo com suas propriedades físicas. Na Tabela 1, são apresentadas as propriedades analisadas nos agregados e as respectivas normas utilizadas.

Tabela 1 - Relação dos ensaios de caracterização física para os agregados

\begin{tabular}{c|c|c}
\hline Propriedades & Agregado Miúdo & Agregado Graúdo \\
\hline Massa específica & NBR NM 52 (ABNT, 2009) & NBR NM 53 (ABNT, 2009) \\
\hline Absorção de água & -- & NBR NM 53 (ABNT, 2009) \\
\hline Granulometria & NBR NM 248 (ABNT, 2003) & NBR NM 248 (ABNT, 2003) \\
\hline
\end{tabular}

Além disso, a resistência ao esmagamento foi analisada para os agregados graúdos, cujo ensaio mede de forma indireta a resistência do agregado, através da sua capacidade de se manter íntegro sob aplicação de determinada carga, conforme NBR 9938 (2013). O ensaio consiste em preencher um êmbolo cilíndrico com esse agregado graúdo, em uma granulometria de $9,5 \mathrm{~mm}$, e aplicar $400 \mathrm{KN}$. Após esse procedimento, verifica-se qual a porcentagem que fica retido na peneira 2,4 mm. Assim, a resistência ao esmagamento é a porcentagem desse material passante na peneira de $2,4 \mathrm{~mm}$.

A adição mineral, powder LD, foi caracterizada, através da granulometria e massa específica. Para se obter a granulometria foi utilizada a técnica de difração de laser (Bettersize 2000), cuja água destilada era o meio dispersor. A granulometria do cimento CP IV foi obtida utilizando, também, a técnica de difração de laser (Bettersize 2000), cujo álcool isopropílico era o meio dispersor. 


\subsubsection{Estudo de dosagem e fabricação dos concretos}

O consumo de cimento foi fixado em $450 \mathrm{~kg} / \mathrm{m}^{3}$ para fabricar concretos que fossem fisicamente iguais e com a menor variação de parâmetros possíveis. O teor fixo de argamassa adotado foi de 59\%, de acordo com a metodologia do Instituto de Pesquisa Tecnológica (IPT) e o fator água/aglomerantes foi fixado para todos os concretos produzidos com esse consumo de cimento. O slump, de acordo com a NBR 7212 (ABNT 2012), foi definido em $90 \mathrm{~mm}$ com a tolerância de $10 \mathrm{~mm}$. O powder LD foi utilizado em teores de $8 \%$ e $14 \%$ em volume.

Para melhorar o desempenho da matriz, a quantidade de cimento não foi substituída pela adição. Com isso, definiu-se os traços, sendo: traços de referência (REF), compostos de agregados convencionais com e sem adição de powder e traços de escória de aciaria (ELD), compostos de agregado de escória com e sem adição de powder LD. Cada traço recebeu uma identificação no qual a o código inicial corresponde ao tipo de agregado (REF e ELD), seguido do teor do powder LD: 8\% (P8) e 14\% (P14). Na Tabela 2, é apresentado as proporções dos concretos em relação ao consumo de cimento.

Tabela 2 - Traços dos concretos em relação ao consumo de cimento

\begin{tabular}{|c|c|c|c|c|c|c|c|}
\hline Traço & $\begin{array}{c}\text { Água/ } \\
\text { aglomerantes }\end{array}$ & $\begin{array}{c}\text { Cimento } \\
\left(\mathrm{kg} / \mathrm{m}^{3}\right)\end{array}$ & $\begin{array}{l}\text { A. miúdo } \\
\left(\mathrm{kg} / \mathrm{m}^{3}\right)\end{array}$ & $\begin{array}{l}\text { A. Graúdo } \\
\left(\mathrm{kg} / \mathrm{m}^{3}\right)\end{array}$ & $\begin{array}{l}\text { Água } \\
\left(\mathrm{kg} / \mathrm{m}^{3}\right)\end{array}$ & $\begin{array}{l}\text { Adição } \\
\left(\mathrm{kg} / \mathrm{m}^{3}\right)\end{array}$ & $\begin{array}{c}\text { Aditivo } \\
(\%)\end{array}$ \\
\hline REF - 0 & \multirow{6}{*}{0,44} & \multirow{6}{*}{450} & 818,29 & 881,36 & 198,00 & 0 & 0,25 \\
\hline REF - P8 & & & 764,40 & 843,90 & 219,90 & 49,77 & 0,20 \\
\hline REF - P14 & & & 723,78 & 815,67 & 236,32 & 87,10 & 0,05 \\
\hline ELD - 0 & & & 1224,77 & 1163,83 & 198,00 & 0 & 0,35 \\
\hline ELD - P8 & & & 1147,78 & 1110,32 & 219,90 & 49,77 & 0,33 \\
\hline ELD - P14 & & & 1090,43 & 1070,47 & 236,62 & 87,10 & 0,20 \\
\hline
\end{tabular}

Para verificar qual seria a melhor ordem de mistura dos materiais foi realizada uma série de testes de concretagem. A opção mais eficiente para melhor homogeneização foi aquela onde as adições minerais foram incorporadas à agua junto com o aditivo, assim obteve-se maior dispersão das partículas e melhor trabalhabilidade no estado fresco do concreto. A ordem de preparo foi: agregado graúdo; $1 / 3$ da água; cimento; $1 / 3$ da água; agregado miúdo; $1 / 3$ da água.

O tempo para mistura foi de 30 segundos para as primeiras etapas e 5 minutos para homogeneização total, após todos os materiais terem sido adicionados a betoneira. $\mathrm{O}$ intervalo máximo de fabricação do concreto foi de 1 hora. Atendendo a prescrição da NBR 5738 (2015) com relação a proporção do DMC dos agregados graúdos e o diâmetro dos corpos de prova, foram moldados corpos de prova cilíndricos de $5 \times 10 \mathrm{~cm}$. Os mesmos foram adensados com 20 golpes na mesa de fluxo, curados em câmara úmida com umidade e temperatura controlada $\left(23 \pm 2^{\circ} \mathrm{C}\right.$ e $\left.95 \%\right)$.

\subsubsection{Caracterização física e mecânica dos concretos}

Os concretos foram caracterizados quanto as suas propriedades físicas e mecânicas na idade de 28 dias. Para a realização do ensaio mecânico (resistência à compressão), utilizou-se a prensa hidráulica EMIC DL 20000, com célula de carga de $200 \mathrm{kN}$ e velocidade de 0,3 MPa/s. Já no ensaio de velocidade de pulso ultrassônico (VPU), utilizou-se o equipamento TICO (Proceq) com pulsos ultrassônicos de 54Hz e medições diretas. Assim, com base no resultado da velocidade de pulso ultrassônico (VPU) os concretos foram classificados, de acordo com sua integridade e qualidade.

Segundo Saxena et al. (2018) e Saint-Pierre et al. (2016), o concreto pode ser classificado de acordo com sua velocidade de pulso, como: excelente $(>4500 \mathrm{~m} / \mathrm{s})$; bom $(4500-3500 \mathrm{~m} / \mathrm{s})$; duvidoso $(3500-3000 \mathrm{~m} / \mathrm{s})$; e pobre $(<3000 \mathrm{~m} / \mathrm{s})$. $\mathrm{Na}$ Tabela 3 consta os ensaios realizados para caracterização física e mecânica dos concretos com as respectivas normas e número de repetições.

Tabela 3 - Ensaios e respectivos protocolos de caracterização dos concretos

\begin{tabular}{c|c|c}
\hline Ensaio & $\begin{array}{c}\text { Número de repetições } \\
\text { por traço }\end{array}$ & Normatização \\
\hline Massa específica & 3 & NBR 9778:2005 (ABNT, 2005) \\
\hline Absorção de água por imersão & 3 & NBR 9778:2005 (ABNT, 2005) \\
\hline Resistência à compressão & 4 & NBR 5739:2018 (ABNT, 2018) \\
\hline Velocidade Pulso Ultrassônico (VPU) & 16 & NBR 8802:2013 (ABNT, 2013) \\
\hline
\end{tabular}




\subsubsection{Análise de durabilidade}

A técnica adaptada NT Build 443 (1995), foi utilizada para avaliar a capacidade que os concretos tinham em resistir a penetração de cloretos. Essa técnica, consiste no corpo de prova de concreto ficar imerso em uma solução de $\mathrm{NaCl}$ por um tempo de 35 dias (tempo mínimo). Assim, os corpos de prova do estudo foram colocados imersos nessa solução na idade de 56 dias. Na Tabela 4 as etapas de preparação dos corpos de provas são descritas:

Tabela 4: Etapas de preparação dos corpos de prova

\begin{tabular}{c|c}
\hline ETAPAS & DESCRIÇÃO \\
\hline $\begin{array}{c}\text { 1. Regularização da face } \\
\text { superior dos corpos de prova }\end{array}$ & $\begin{array}{c}\text { Retirada de 0,5 cm das face superior do corpo de prova utilizando uma serra } \\
\text { diamantada para facilitar o acesso da solução agressiva na matriz. Posteriormente } \\
\text { as faces foram polidas (lixa da água } \mathrm{n}^{\circ} \text { 80), garantindo mínima rugosidade. }\end{array}$ \\
\hline $\begin{array}{c}\text { 2. Limpeza e estufa } \\
\text { A face superior dos corpos de provas foi lavados e levados para estufa a } 40^{\circ} \mathrm{C} \text { até } \\
\text { atingir constância de massa de 5\%, garantindo a eliminação da água livre na } \\
\text { superfície sem comprometer a estrutura. }\end{array}$ \\
$\begin{array}{c}\text { 3. Imersão em solução } \\
\text { saturada de cal }\end{array}$ & $\begin{array}{c}\text { Após os corpos de prova terem secados na estufa, eles foram imersos nessa } \\
\text { solução até constância de massa de 0,1\%. }\end{array}$ \\
\hline $\begin{array}{c}\text { 4. Envelopamento e } \\
\text { recobrimento }\end{array}$ & $\begin{array}{c}\text { Os corpos de prova foram envelopados com fita adesiva reforçada e recobertos } \\
\text { com parafina para garantir eficiência no sistema de vedação. Assim, só a face que } \\
\text { foi lixada ficou livre para o ataque de cloretos. }\end{array}$ \\
\hline
\end{tabular}

Após toda a preparação, os corpos de prova receberam dispositivos tubulares feitos de PVC (policloreto de polivilina) com juntas de silicone. O recipiente de PVC foi preenchido com solução de $\mathrm{NaCl}$ na concentração de $16,5 \%(2,85$ mol/litro). Assim, esses corpos de prova foram expostos a essa solução em uma única direção de penetração por dois períodos: 35 e 55 dias, realizando-se duas repetições para cada traço. Os corpos de prova foram monitorados diariamente e trocado a solução a cada 15 dias. Na Figura 1, é apresentado o corpo de prova já preparado para receber a solução de $\mathrm{NaCl}$.

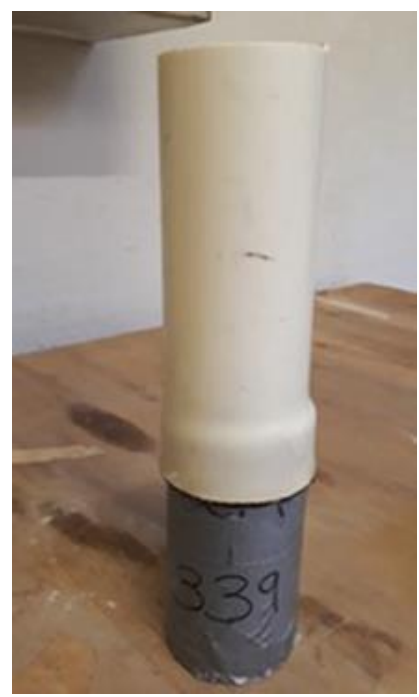

Figura 1: Corpo de prova preparado para análise

Para avaliar e quantificar a profundidade da penetração de cloretos, seccionou-se os corpos de prova ao meio (ao longo da geratriz) e foi aspergido solução de nitrato de prata que indicava a profundidade de penetração de cloretos na região. Com o auxílio de um paquímetro de $0,1 \mathrm{~mm}$ de precisão foi medido a profundidade que teve essa penetração. A Figura 2 apresenta o corpo de prova após a aspersão do nitrato de prata. 


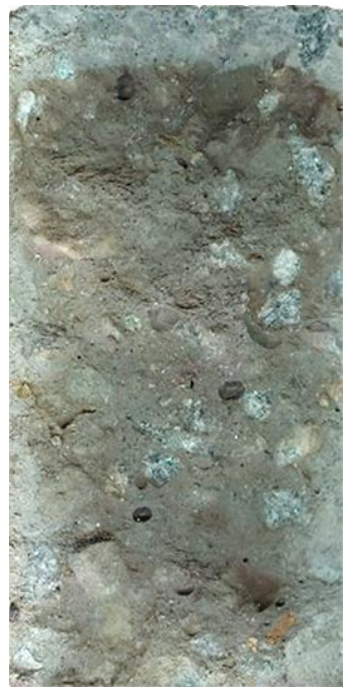

Figura 2: Corpo de prova após a aspersão de nitrato de prata

\section{RESULTADOS E DISCUSSÕES}

\subsubsection{Caracterização dos agregados e da adição}

A composição química da escória de aciaria, obtida pela fluorescência de Raio-X é apresentada na Tabela 5.

Tabela 5 - FRX das frações obtidas durante a separação magnética

\begin{tabular}{c|c}
\hline & Escória de aciaria LD \\
\hline $\mathrm{MgO}$ & $5,1 \%$ \\
\hline $\mathrm{Al}_{2} \mathrm{O}_{3}$ & $4,4 \%$ \\
\hline $\mathrm{SiO} 2$ & $15,6 \%$ \\
\hline $\mathrm{P}_{2} \mathrm{O}_{5}$ & $1,5 \%$ \\
\hline $\mathrm{CaO}$ & $36,8 \%$ \\
\hline $\mathrm{MnO}$ & $3,5 \%$ \\
\hline $\mathrm{Fe}_{2} \mathrm{O}_{3}$ & $31,2 \%$ \\
\hline $\mathrm{Outros}$ & $1,9 \%$ \\
\hline
\end{tabular}

Analisando os resultados, observa-se altos teores de $\mathrm{Fe}_{2} \mathrm{O}_{3}, \mathrm{MgO}$ e $\mathrm{CaO}$. Para que esse ensaio de FRX fosse realizado, o material teve de ser fragmentado até passar na peneira de $0,075 \mathrm{~mm}$ de abertura, então acredita-se que grande parte do ferro encontrado (identificado como $\mathrm{Fe}_{2} \mathrm{O}_{3}$ ) foi liberado do interior da escória de aciaria. Ressalta-se, também, que apesar dos altos teores de $\mathrm{MgO}$ e $\mathrm{CaO}$ encontrados, acredita-se que estes estariam combinados a outros componentes, como indicado na literatura por Andrade (2018) e Diniz et al (2017).

A Figura 3 apresenta as curvas granulométricas dos agregados. Buscou-se no estudo, ter agregados com uma granulometria igual para assim produzir concretos fisicamente semelhantes, ambos foram projetados para atender a zona ótima, segundo a norma NBR 7211. 


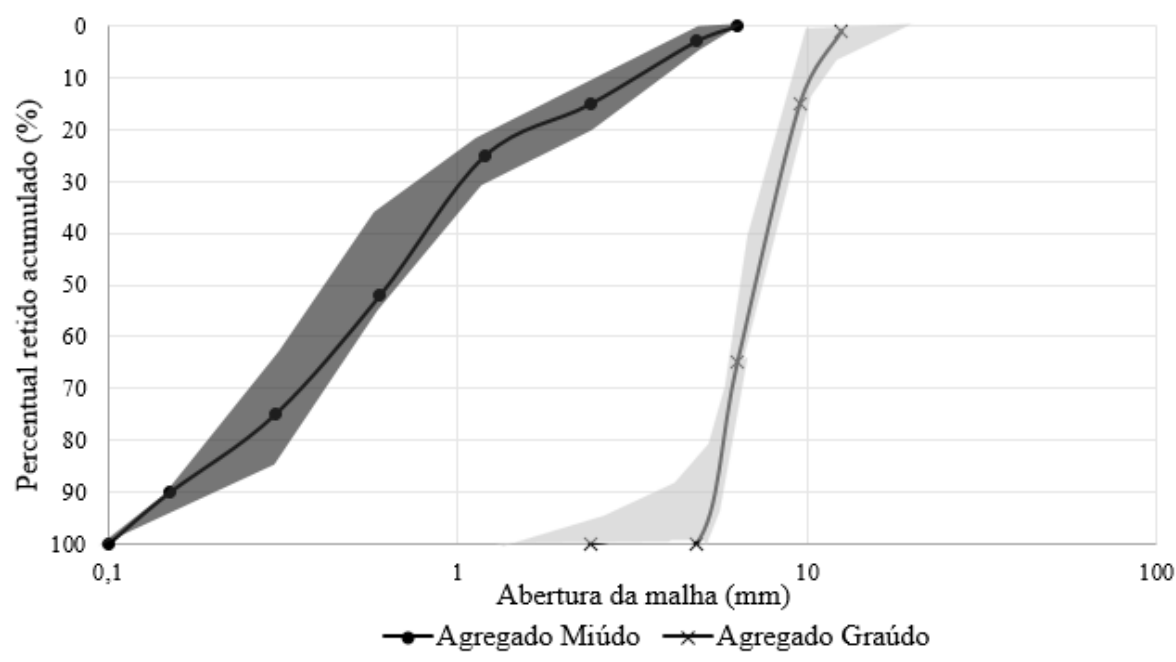

Figura 3: Distribuição granulométrica do agregado graúdo e miúdo utilizado no estudo

As características físicas e mecânica dos agregados convencionais e de escória de aciaria são apresentadas na Tabela 6 . Observa-se que, a massa específica dos agregados de escória é maior que dos agregados convencionais, devido a sua composição rica em metais como cálcio e ferro. O agregado miúdo de escória apresenta a massa específica $28,34 \%$ superior que o agregado miúdo convencional, enquanto que o graúdo de escória é 27,04\% superior do que o convencional.

Tabela 6 - Caracterização física e mecânica dos agregados utilizados

\begin{tabular}{c|c|c|c|c}
\hline & A. miúdo LD & $\begin{array}{c}\text { A. miúdo } \\
\text { convencional }\end{array}$ & A. graúdo LD & $\begin{array}{c}\text { A. graúdo } \\
\text { convencional }\end{array}$ \\
\hline Massa específica & $3,74 \mathrm{~g} / \mathrm{cm}^{3}$ & $2,68 \mathrm{~g} / \mathrm{cm}^{3}$ & $3,58 \mathrm{~g} / \mathrm{cm}^{3}$ & $2,61 \mathrm{~g} / \mathrm{cm}^{3}$ \\
\hline Absorção de água & -- & -- & $1,54 \%$ & $1,29 \%$ \\
\hline DMC & $4,8 \mathrm{~mm}$ & $4,8 \mathrm{~mm}$ & $12,5 \mathrm{~mm}$ & $12,5 \mathrm{~mm}$ \\
\hline Resistência ao Esmagamento & -- & -- & $89,41 \%$ & $82,92 \%$ \\
\hline
\end{tabular}

A absorção de água dos agregados convencionais e de escória foram semelhantes. Quanto a resistência ao esmagamento, observa-se que o agregado de escória de aciaria foi cerca de $38 \%$ mais resistente que o agregado convencional. Esse fato, pode ser explicado pela morfologia dos agregados, pois o agregado de escória apresenta-se na forma cúbica e o agregado convencional na forma lamelar. A forma lamelar dos grãos contribui para a redução da resistência.

A Figura 4 apresenta a curva granulométrica do powder LD e do cimento. Observa-se que essa adição mineral de powder possui diâmetro dos grãos menor que o cimento CP IV. Analisando o diâmetro característico D90 desses materiais,

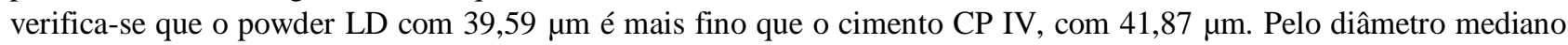
D50 o powder se mantém como mais fino, com $8,55 \mu \mathrm{m}$, enquanto o cimento tem $12,97 \mu \mathrm{m}$. A massa específica do powder é $3,74 \mathrm{~g} / \mathrm{cm}^{3}$ enquanto a do cimento é, segundo a literatura, $3,01 \mathrm{~g} / \mathrm{cm}^{3}$. O valor superior de massa específica do powder LD já era esperado, devido a sua composição com altos teores de $\mathrm{CaO}, \mathrm{SiO}_{2}$ e $\mathrm{Fe}_{2} \mathrm{O}_{3}$ (SILVA, SOUZA, et al., 2016). 


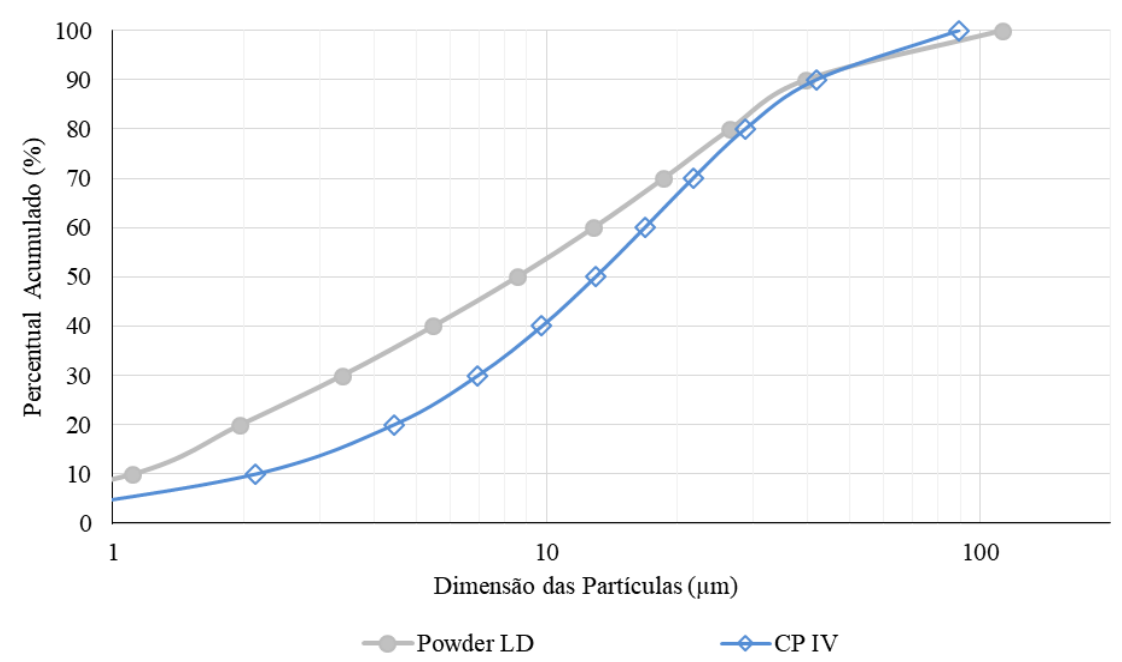

Figura 4: Distribuição granulométrica da adição mineral e do cimento utilizado

\subsubsection{Caracterização do concreto}

A Figura 5 apresenta os resultados de massa específica e absorção de água por imersão.

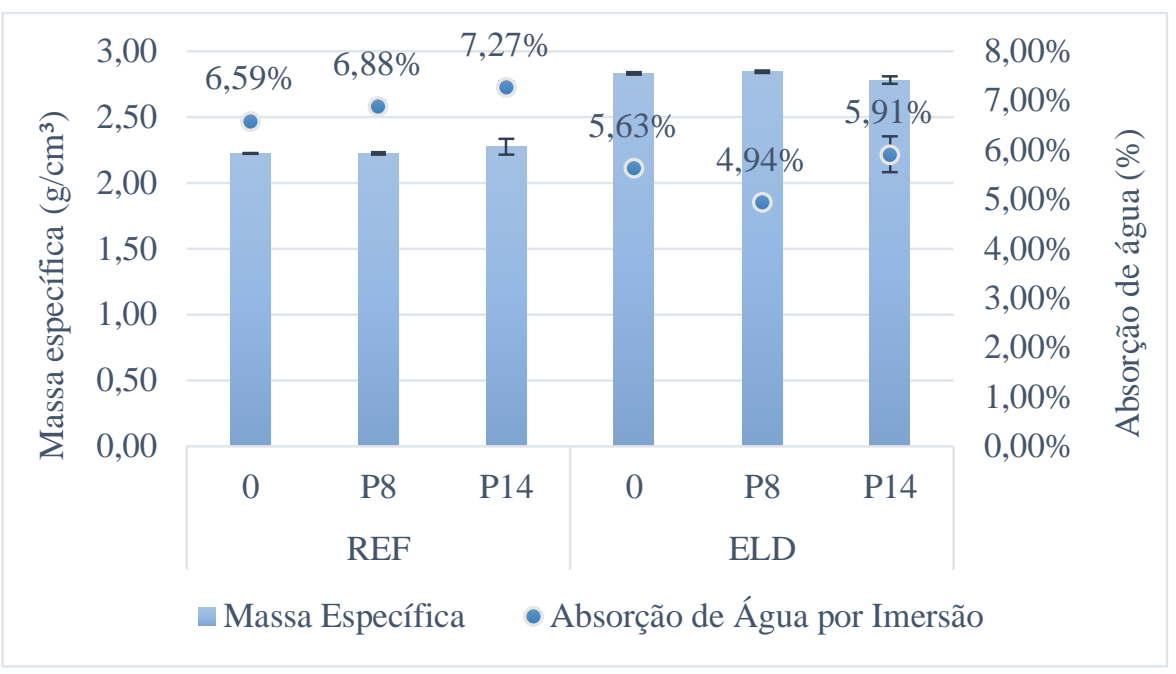

Figura 5: Massa específica e absorção de água dos concretos fabricados

Analisando as massas específicas dos concretos produzidos, verificou-se que aqueles fabricados com agregados de referência tiveram massa específica média de $2,24 \mathrm{~g} / \mathrm{cm}^{3}$, enquanto que os que possuíam agregados de escória de aciaria tiveram massa específica de $2,82 \mathrm{~g} / \mathrm{cm}^{3}$. Os valores cerca de $25 \%$ superiores encontrados para os concretos ELD eram esperados, já que a massa específica dos agregados de escória é 38\% superior ao de agregados convencionais.

Quanto à absorção de água, os concretos com agregados de referência tiveram absorção de água média de 6,9\% e os concretos com agregados de escória foi de 5,5\%. Assim, os concretos ELD absorveram aproximadamente 20\% menos água que os concretos de referência. Os concretos REF e ELD com adição de 14\% de powder LD absorveram mais água em comparação aos concretos sem adição. Isso se deve ao fato que o percentual de adição foi projetado em volume, para que os efeitos fossem avaliados de forma equivalente, porém o fator água/aglomerantes foi usado em massa. Assim, todos possuíam mesmo volume de finos, porém massa diferente de adição. Isso, resultou no maior consumo de água nos concretos que tiveram adições de powder LD devido a sua maior massa específica.

A Figura 6 apresenta os resultados de velocidade de pulso ultrassônico e a resistência à compressão na idade de 28 dias dos concretos produzidos. 


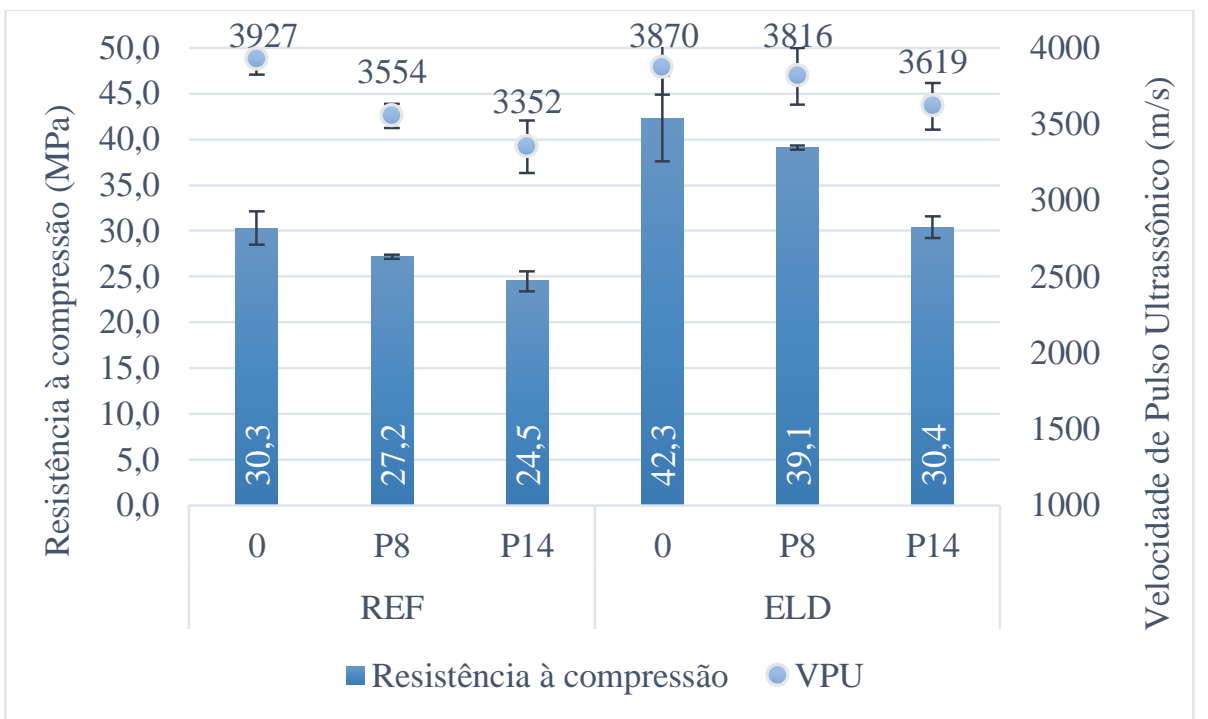

Figura 6: Velocidade de Pulso Ultrassônico e resistência à compressão dos concretos fabricados

No geral, os concretos fabricados foram classificados como matrizes de boa qualidade, cujo intervalo de VPU é: 3500 $\mathrm{m} / \mathrm{s}<$ VPU $<4500 \mathrm{~m} / \mathrm{s}$. Apenas, o concreto REF-P8 apresentou o VPU menor do que $3500 \mathrm{~m} / \mathrm{s}$. A velocidade de pulso ultrassônico (VPU) é relacionada, principalmente, com a estrutura de poros e sua homogeneidade, ou seja, quanto menos poroso for o concreto maior será essa velocidade significando uma matriz com menos imperfeições.

Os concretos com agregado de escória de aciaria apresentaram uma resistência à compressão média de 37,3MPa, enquanto os concretos com agregados convencionais apresentaram uma resistência média de 22,4MPa. Assim, em termos de resistência mecânica os concretos de escória são 66,5\% superiores aqueles com agregados convencionais. Esse resultado demonstra que a escolha do tipo de agregado é determinante para o desempenho mecânico das matrizes cimentícias principalmente nos concretos estudados em que sua classe de resistência é inferior a $40 \mathrm{MPa}$. Sabe-se que para esses concretos a ruptura é comandada pelo agregado graúdo (MEHTA e MONTEIRO, 2006; TAYLOR, 1997). Assim, utilizar agregados mais resistentes implica no aumento da resistência à compressão do concreto, como os agregados de escória de aciaria que apresentou uma resistência ao esmagamento 38\% superior ao agregado convencional de gnaisse. A morfologia da escória de aciaria também contribui para o melhor desempenho mecânico dos concretos, pois possuem uma superfície rugosa com poros abertos que diminui e torna menos porosa a zona de transição interfacial (ZTI) do agregado-argamassa.

Os concretos produzidos com powders LD (P8 e P14) apresentaram bom desempenho mecânico. A resistência média das matrizes com $8 \%$ de powder foi de 33,15 Mpa e com 14\% de 27,45 MPa, enquanto para os concretos sem adição essa resistência média foi de 36,3 MPa. Porém, ressalta-se que, as matrizes contendo powder $8 \%$ (P8) tiveram um consumo de água de $219 \mathrm{~kg} / \mathrm{m}^{3}$, enquanto as matrizes de powder $14 \%$ (P14) consumiram $236 \mathrm{~kg} / \mathrm{m}^{3}$ e os sem adição $198 \mathrm{~kg} / \mathrm{m}^{3}$. Esse maior consumo de água nos concretos P14 pode ter ocasionado a menor resistência quando comparado aos sem adição. Portanto, corrigindo esse parâmetro a resistência dos concretos com powder 14\% (P14) será mais próxima ou superior dos concretos sem adição.

\subsubsection{Durabilidade do Concreto}

A Figura 8 apresenta os resultados obtidos em relação à profundidade penetrada por cloretos. 


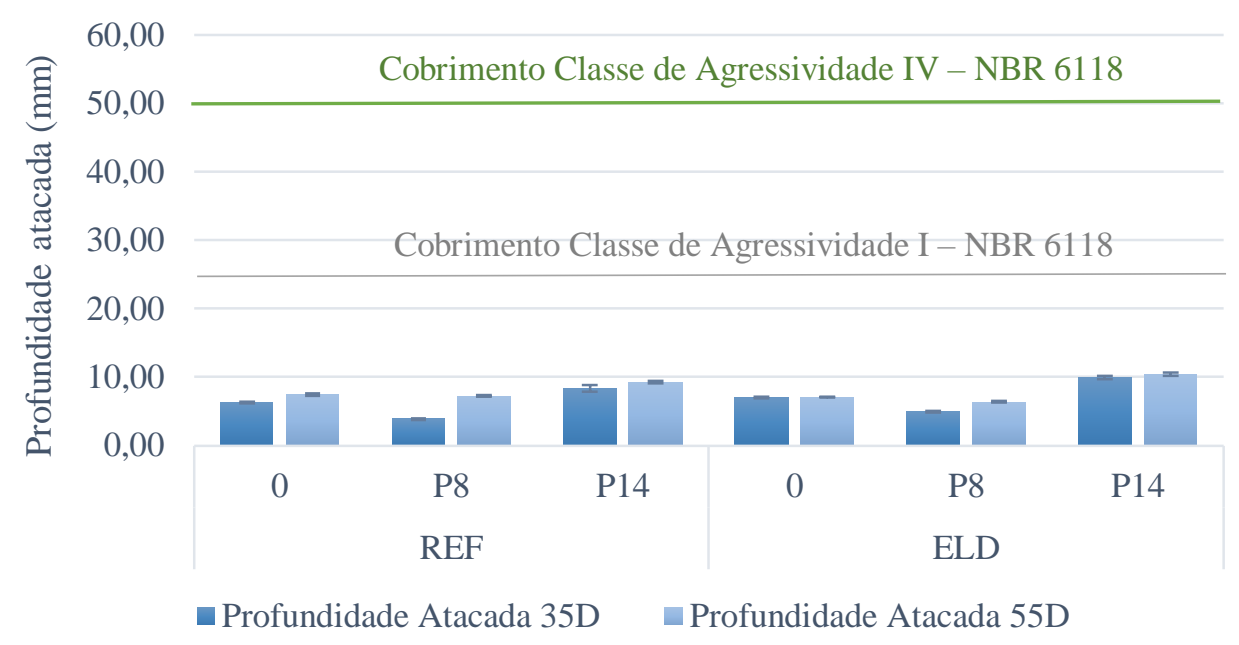

Figura 7: Gráfico com a profundidade e a área atacada por cloretos, nas idades de 35 e 55 dias

Analisando os resultados, observou-se que a utilização de agregados de escória de aciaria não prejudicou o desempenho das matrizes frente a cloretos, obtendo resultado similar. Aqueles concretos fabricados com agregado de escória de aciaria tiveram profundidade atacada em média de 7,94 $\mathrm{mm}$ enquanto os convencionais de 7,96 $\mathrm{mm}$. Os concretos com adição de powder LD tiveram valores superiores de profundidade atacada comparados aos concretos produzidos sem adição. Porém, ressalta-se que, os concretos com essa adição tiveram uma profundidade de penetração, para as duas idades, inferior a $10 \mathrm{~mm}$ e sabe-se que o cobrimento mínimo das armaduras (em regiões de baixa agressividade, Classe I) é de 25 mm, segundo NBR 6118 (2013). Isso indica que os concretos fabricados com powder LD são considerados duráveis e com bom desempenho, mesmo tendo uma maior penetração do que aqueles sem adição. Baseado no parâmetro de penetração de cloretos os concretos com $8 \%$ de powder LD são mais indicados para utilização, pois apresentaram a profundidade penetrada $33,6 \%$ menor do que os concretos sem adição para o período de 35 dias.

\section{CONCLUSÃO}

O presente estudo mostrou que o uso da escória de aciaria como agregado ocasionou um aumento na resistência à compressão, devido à sua morfologia e a resistência desse agregado ser maior que a dos convencionais. Porém, nos concretos produzidos com a adição mineral de escória de aciaria a resistência foi inferior ao dos concretos sem adição. Observou-se, também, que a massa específica dos concretos produzidos com os agregados de escória são superiores ao dos concretos convencionais, devido a massa específica desses agregados serem maiores que dos agregados convencionais. Entretanto, os concretos de escória de aciaria ainda são classificados como concretos normais.

Quanto ao uso da escória como adição mineral, conclui-se que o powder LD contribui no desempenho do concreto não afetando negativamente nenhuma das suas propriedades. A dosagem de $8 \%$ mostrou-se mais eficiente para incorporação em concretos. Além disso, os concretos produzidos com escória de aciaria foram menos atacados por cloretos em relação aos concretos convencionais.

Considera-se ainda que os concretos com powder LD tinham um maior teor de água, devido ao critério de dosagem e a elevada massa específica do material. Espera-se que para condição de fabricação com mesmo teor de água os resultados seriam superiores. Apesar disso, observou-se que esses concretos tiveram bons resultados de desempenho mecânico e durabilidade, sendo estes inferiores ao cobrimento mínimo exigido em norma para ambientes de baixa agressividade (classe I). Assim, conclui-se o uso dessa escória em concretos pode produzir matrizes mais eficientes que as matrizes convencionais e, consequentemente, com melhor desempenho mecânico e maior durabilidade.

\section{AGRADECIMENTOS}

O presente trabalho foi realizado com apoio da Coordenação de Aperfeiçoamento de Pessoal de Nível Superior - Brasil (CAPES) - Código de Financiamento 001. Os autores, também, agradecem à FAPEMIG, CNPq e UFOP pelo apoio para a realização e apresentação dessa pesquisa. Também somos gratos pela infraestrutura e colaboração do Grupo de Pesquisa em Resíduos Sólidos - RECICLOS - CNPq. 


\section{REFERÊNCIAS}

ABNT. NBR NM 52: Agregado miúdo - Determinação da massa específica e massa específica aparente. Rio de Janeiro: Associação Brasileira de Normas Técnicas, 2009.

ABNT. NBR NM 248: Agregados - Determinação da composição granulométrica. Rio de Janeiro: Associação Brasileira de Normas Técnicas, 2003.

ABNT. NBR 9938: Agregados - Determinação da resistência ao esmagamento de agregados graúdos - Método de ensaio. Rio de Janeiro: Associação Brasileira de Normas Técnicas, 2013.

ABNT. NBR 9778: Argamassa e concreto endurecidos - Determinação da absorção de água, índice de vazios e massa específica. Rio de Janeiro: Associação Brasileira de Normas Técnicas, 2005.

ABNT. NBR 7211: Agregado para concreto - Especificação. Rio de Janeiro: [s.n.], 2009.

ABNT. NBR NM 53: Agregado graúdo - Determinação de massa específica, massa específica aparente e absorção de água. Rio de Janeiro: Associação Brasileira de Normas Técnicas, 2009.

ABNT. NBR 6118: Projeto de estruturas de concreto - Procedimento. Rio de Janeiro: Associação Brasileira de Normas Técnicas, 2013.

ABNT. NBR 8802: Concreto endurecido - Determinação da velocidade de propagação de onda ultrassônica. Rio de Janeiro: Associação Brasileira de Normas Técnicas, 2013.

ABNT. NBR 5738: Concreto - Procedimento para moldagem e cura de corpos de prova. RIo de JAneiro: Associação Brasileira de Normas Técnicas, 2015.

ABNT. NBR 5739: Concreto - Ensaio de compressão de corpos de prova cilíndricos. Rio de Janeiro: Associação Brasileira de Normas Técnicas, 2018.

ANDRADE, H. D. Carbonatação em Concretos de Escória de Aciaria. Ouro Preto: Diss. Mestrado, 2018.

ANEPAC. Relatório: O Mercado de agregado no Brasil. São Paulo: Associação Nacional das Entidades de Produtores de Agregados para Construção, 2015.

ARRIBAS, I. . V. I. . S.-J. J. \&. M. J. Durability studies on steelmaking slag concretes. Materials and Design, p. vol 63; p. 168-176, 2014.

BERTOLINI, L. ET AL. Corrosion of Steel in Concrete and Its Prevention in Aggressive Chloride-Bearing Environments. 5th International Conference on Durability of Concrete Structures. Italy: [s.n.]. 2016.

BISKRI, Y. . A. D. . C. N. \&. M. M. Mechanical and durability characteristics of High Performance Concrete containing steel slag and crystalized slag as aggregates. Construction and Building Materials, p. vol 150; p. 167-178, 2017.

DINIZ, D. H. et al. Blast Oxygen Furnace Slag as Chemical Soil Stabilizer for Use in Roads. Journal of Materials in Civil Engineering, v. 29, 2017.

GENG, C. et al. A time-saving method to determine the chloride threshold level for depassivation of steel in concrete. Construction and Building Materials, v. 24, p. 903-909, 2010.

IABR. Relatório de Sustentabilidade 2016-2017. Instituto Aço, 2018.

MEDEIROS, M. H. F., ET AL. Durabilidade e Vida Útil das Estruturas de Concreto. Concreto: Ciência e Tecnologia. IBRACON, 2011.

MEHTA, P. K.; MONTEIRO, P. J. M. Concrete: Microstrucuture, Properties and Materials. New York: McGraw-Hill, 2006. 
MONOSI, S. . R. M. \&. S. D. Electric arc furnace slag as natural aggregate replacement in concrete production. Cement and Concrete Composites, p. vol 66; p. 66-72, 2016.

NORDTEST. NT Build 443: Concrete Hardened - Accelerated Chloride Penetration. Espoo: Nordtest Methods, 1995.

SAINT-PIERRE, F. et al. Concrete Quality Designation based on Ultrasonic Pulse Velocity. Construction and Building Materials, v. 125, p. 1022-1027, 2016.

SAN-JOSÉ, J. . V. I. . A. I. \&. M. I. The performance of steel-making slag concretes in the hardened state. Materials and Design, p. vol 60; p. 612-619, 2014.

SANTAMARIA, A. . O. A. . S. J. J. \&. G. J. A study on the durability of structural concrete incorporating electric steelmaking slags. Construction and Building Materials, p. vol 161; p. 94-111, 2018.

SAXENA, S.; TEMBHURKAR, A. Impact of use of steel slag as coarse aggregate and wastewater on fresh and hardened properties of concrete. Construction and Building Materials, p. 126-137, 2018.

SILVA, M. J. et al. Feasibility Study of Steel Slag Aggregates in Precast Concrete Pavers. ACI MATERIALS JOURNAL, v. 113, p. 439-446, 2016.

SOUZA, L. Estudo dos efeitos do uso da escória de aciaria na expansão de corpos de prova sujeitos à reação álcaliagregado. REVISTA IBRACON DE ESTRUTURAS E MATERIAIS, p. vol 9; p. 572-586, 2016.

TAYLOR, H. F. W. Cement Chemistry. [S.1.]: Thomas Telford Publishing, 1997.

YOUNG, J.; FRANCIS, A.; MINDESS, S. The science and technology of civil engineering materials. New Jersey: Prentice Hall, 1998. 